\title{
SSinteza
}

Impact of Internet on Business Activities in Serbia and Worldwide

Uticaj Interneta na poslovanje u Srbiji i svetu

DOI: 10.15308/SINTEZA-2014-868-871

\section{KOMPOZITNA ANALIZA TEHNIČKE INFRASTRUKTURE MODELA SPI_PIO_RS}

\author{
Mladen Milić \\ Fond PIO Republike Srpske
}

\begin{abstract}
:
Integrisani informacioni sistem (IIS) Fonda PIO (Fond) čini srce ove institucije iz čijih baza se crpe podaci potrebni za ostvarivanje prava, izveštavanje, planiranje, analiziranje i odlučivanje. Svrha ove analize jeste prikaz infrastrukture modela sistema poslovne inteligencije Fonda. Analiza obuhvata baze podataka koji se koriste za podršku odlučivanju, njihovo ažuriranje i strukturiranje. Kao izvori podataka u Fondu identifikovani su: baza podataka ključnih poslovnih procesa, ERP baza podataka, istorijski podaci, eksterni i drugi relevantni podaci. Izvorne podatke za Data Warehouse (DW) bazu formiraju transakcioni procesi koji se dešavaju u sledećim poslovnim procesima i aktivnostima: M1-Matična evidencija osiguranika, M2-Matična evidencija korisnika prava, M4-Likvidatura penzija, M5-Praćenje naplate doprinosa (evidentiranje i praćenje doprinosa, izveštaji), M8-Obaveza Republike (insert podataka potrebnih za izračunavanje obaveze). Svi podaci koje generišu ovi procesi i evidencije se roje oko jezgra informacionog sistema (JIS). Ovi podaci, ujedno predstavljaju i najsnažnije izvorište DW baze.

Svi ovi procesi međusobno su uvezani u IIS Fonda, a odvijaju se uz pomoć četiri servera i to: ETL, DW, OLAP i WEB. Krajnji korisnici, iako geografski rasprostranjeni po celoj Republici Srpskoj imaju mogućnost pristupa, putem Intraneta i/ili Interneta, WEB Serveru i analitičkim aplikacijama putem kojih se kreiraju, sačinjavaju izveštaji i analiziraju podaci, koji se pretvaraju u informacije potrebne za poslovno odlučivanje, rešavanje poslovnih zadataka i ostvarivanje poslovnih ciljeva.
\end{abstract}

\section{Key words:}

podatak, baza podataka, server, odlučivanje, integrisani informacioni sistem.

\section{UVOD}

U operativnom informacionom sistemu Fonda nalaze se ulazni podaci za sistem i izvorišta podataka. Operativni podaci odslikavaju svakodnevne elementarne poslovne događaje i zajedno sa podacima za podršku odlučivanju koriste se u različite svrhe. Ovi podaci nalaze se u normalizovanim relacionim bazama podataka. Normalizacijom se podaci o entitetima, koji su u realnom svetu međusobno povezani, raspoređuju u više baznih relacija. $\mathrm{Na}$ taj način se izbegavaju anomalije ažuriranja, ali se pri upitima mora vršiti prirodno spajanje tih relacija. Pošto je prirodno spajanje vremenski, relativno skupa operacija, normalizacija favorizuje efikasno ažuriranje, ali degradira performanse pri izvršavanju upita. Podaci za podršku odlučivanju treba da budu strukturirani tako, da obezbede efikasno izvršavanje upita. Operativni podaci, implicitno, sadrže i podatke za izračunavanje činjenica i podatke direktno, koristiti kao ulaz u modele sistema za podršku odlučivanju.

Međutim, operativni podaci su tako strukturirani da bi, pri njihovom direktnom korišćenju, sistem za podršku odlučivanju bio nedopustivo spor. Zbog toga se podaci za podršku odlučivanju izvode iz operativnih podataka i strukturiraju tako da izvršavanje poslovnih modela bude što brže, a podrška modela odlučivanja što efektnija i efikasnija za Fond.

Pod izvorištima podataka podrazumevamo sve baze podataka, fajlove i bilo koje eksterne izvore u elektronskom obliku koji sadrže podatke, od kojih će se eksplorativnom analizom podataka formirati vredni skupovi informacija potrebni za analizu uspešnosti poslovanja Fonda, odnosno procesa odlučivanja. Kao izvori podataka u Fondu identifikovani su: baza podataka ključnih poslovnih procesa, $E R P$ baza podataka, istorijski podaci i eksterni i drugi relevantni podaci. Baza podataka ključnih poslovnih procesa predstavljena je grafičkim modelom na sl. 1 . 


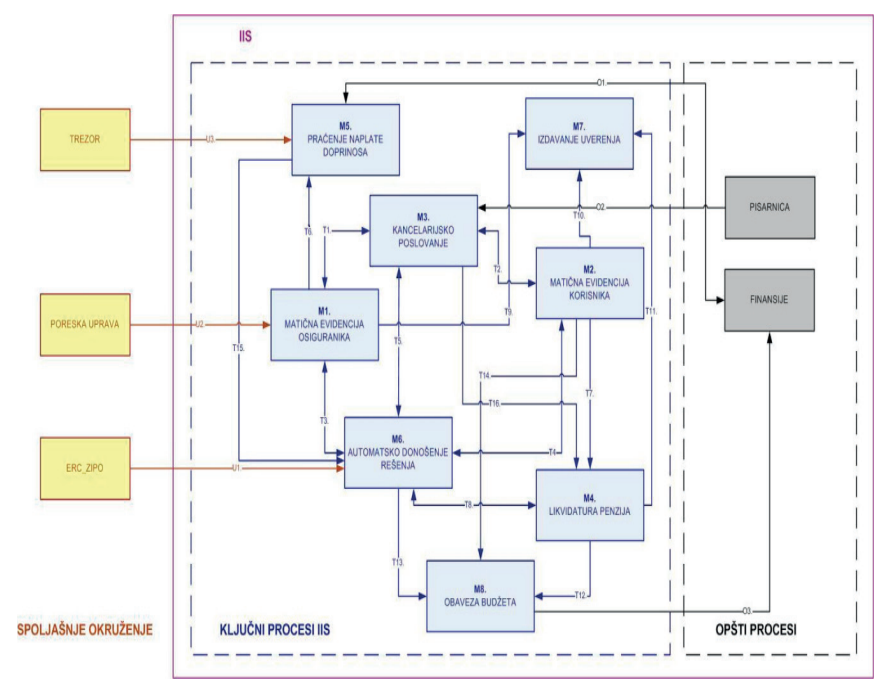

Sl. 1. Baza podataka ključnih poslovnih procesa u Fondu PIO

Izvorne podatke za $D W$ bazu formiraju transakcioni procesi koji se dešavaju u sledećim poslovnim procesima i aktivnostima:

- M1-Matična evidencija osiguranika (unos i ažuriranje podataka o osiguranicima, unos i ažuriranje podataka o uplatiocima doprinosa, izrada raznih pregleda, izveštaja i uverenja koja generišu nove slogove podataka)

- M2-Matična evidencija korisnika prava (unos i ažuriranje podataka o korisnicima uz kontrolne mehanizme provere validnosti podataka, prikaz i štampanje izveštaja, izdavanje uverenja koja generišu nove slogove podataka, eksterni izveštaji i spiskovi-izvoz podataka)

- M4-Likvidatura penzija (pojedinačni unos, preuzimanje i obračun prenzija i drugih primanja mesečni obračun penzija i generisanje listinga za isplatu, kartica penzionera, izveštaji, ulazni podaci, kretanje dokumenta, izvoz podataka)

- M5-Praćenje naplate doprinosa (evidentiranje doprinosa, praćenje doprinosa, izveštaji)

- M8 -Obaveza Republike (insert podataka potrebnih za izračunavanje obaveze, procedura za izračunavanje obaveze, rekapitulacije i spiskovi).

ERP baza podataka je složena, integrisana i ekstremno velika baza standardizovanog softverskog paketa dizajniranog da integriše interni lanac vrednosti organizacije. $E R P$ sistem je zasnovan na integraciji svih poslovnih procesa, svih poslovnih aktivnosti, svih entiteta i transakcija koji generišu velike količine podataka koji se odlažu, smeštaju u ERP bazu podataka. ERP struktura baze podataka Fonda, uglavnom, obuhvata sledeće poslovne procese i aktivnosti: poslovno planiranje, računovodstvo i finansije, nabavka i ljudski resursi. Svi podaci koje generišu ovi procesi i evidencije se roje oko jezgra informacionog sistema (JIS). Ovi podaci predstavljaju najsnažnije izvorište $D W$ baze.

JIS je modul koji obuhvata sve zajedničke podatke ili kompani kog. U njemu se nalaze sve pomoćne evidencije, odnosno sistem šifriranja. Nekoliko desetina šifarnika klasifikovano je u sledeće grupe: opšti šifarnici, podaci o organizaciji, podaci o okruženju, sistemski podaci za ra- čunovodstvo i finansije, sistemski podaci za robno-materijalno poslovanje, sistemski podaci za transport, i dr [1].

Poslovno planiranje je informacioni modul koji se najčešće struktuira u dve celine i to: kreiranje planova i praćenje izvršenja planova. Celina „Kreiranje planova”, dalje se deli u dva dela: identifikacioni deo (planske kategorije, elementarne kategorije, izvedene kategorije, hijerarhijski prikaz kategorija, vrste planova, parametri plana, elementi plana) i kreiranje plana organizacionih delova, kreiranje plana organizacije.

Praćenje izvršenja planova izvodi se kroz "data warehouse rešenje”, odnosno sistem poslovne inteligencije.

Nabavka je važan i podatkovno intenzivan modul $E R P$-a i izvorište podataka za $D W$. Strukturu ovog modula, čine naručivanje i ugovaranje, zaprimanje i upravljanje zalihama. U ovom modulu vodi se KEPU knjiga i generiše preko dvadeset pet raznih izveštaja.

Računovodstvo i finansije se "vrte« oko glavne knjige. Glavna knjiga je sržni deo integralnog sistema i ima za cilj da omogući potpunu integralnu automatizaciju i vođenje računovodstvenih poslova i evidencija. Strukturu ovog modula čine: šifarnici i setup sistema, dokumenta glavne knjige, analitika dobavljača, analitika kupaca, analitika poreza, osnovna sredstva, izveštaji. Tu su još i blagajničko poslovanje, poslovanje sa bankama, obračun zarada, te ostali finansijsko-računovodstveni poslovi.

Upravljanje ljudskim resursima je modul izuzetno dinamičan i u kontinuitetu oformljuje velike količine podataka koji se svakodnevno propagiraju u $D W$ bazu. Subprocesi koji generišu te podatke su: planiranje potreba za ljudskim resursima i zarada, regrutovanje i izbor, zapošljavanje-ugovor o radu, zasnivanje radnog odnosa, raspoređivanje i uvođenje-raspoređivanje na radno mesto, uvođenje u posao, prestanak radnog odnosa-izlazni upitnik, rešenje o prestanku radnog odnosa, evidentiranje i pokretljivost, odsustva sa posla, rešenja, zahtev za godišnji odmor, rešenje o godišnjem odmoru, profesionalni razvoj, razvoj karijere, stručno obrazovanje i usavršavanje, ocenjivanje performanse.

Istorijski podaci su podaci koji se nalaze u bazi matične evidencije korisnika prava i osiguranika, analitičke kartice dobaljavača itd. Ovi podaci imaju longitudinalnu dimenziju, istorijski nastanak, nasleđeni su i kao takvi prenose se u $D W$ bazu.

Eksterni drugi relevantni podaci su podaci koji se nalaze u eksternim bazama podataka i/ili u autarhičnim fajlovima u organizacionim jedinicama Fonda i/ili u Excel fajlovima grupa i pojedinaca, a relevantni su i trebalo bi ih integrisati u jedinstveno skladište podataka.

\section{ETL SERVER}

ETL (Extraction Transformation \& Loading) je posebno važan i složen proces u sistemima poslovne inteligencije, pa tako i u IIS Fonda. Proces obuhvata ekstrakciju podataka, transformisanje i čišćenje izvornih podataka, te njihovo učitavanje u Data Warehouse (skladište podataka). Te procese u velikim sistemima izvršava poseban server, ETL server. U skladu sa definisanom strategijom 
prenosa podataka ETL procesi se izvršavaju automatski putem. Posmatrane sa vremenskog aspekta automatsko izvršavanje je periodično i može biti na dnevnom, nedeljnom i mesečnom nivou.

Za razvoj ETL procesa korišteno je razvojno okruženje pod konvencionalnim nazivom Informix Warehouse Design Studio. Ovo razvojno okruženje je Eclipse-zasnovano okruženje, koje je namenjeno za definisanje izvorišne i ciljne baze podataka DW projekata. Ujedno se inverznim inženjeringom fizičkog modela podataka $D W$ baze gradi $S Q L$ baziran tok podataka i tok kontrole kojim se obavlja brzo, lako, pouzdano i efikasno premeštanje i transformacija podataka iz izvornih sistema u skladište podataka.

\section{DATA WAREHOUSE SERVER}

Svaki poslovni proces, za koji je utvrđeno da operativni podaci omogućavaju izračunavanje činjenica i metrika kao pokazatelja poslovanja i obezbeđenje podataka o činjenicama, sa relativno velikim brojem pojava, postaje bar jedna tema $D W$ baze podataka, odnosno data mart. Data mart $(D M)$ je pragmatična zbirka povezanih činjenica, koje bi trebalo da budu korištene zajedno. DM se obično bira iz jednog poslovnog procesa. Pretpostavimo da je analiza sadržaja operativnih baza podataka pokazala da se za svaki od poslovnih procesa može formirati poseban data mart, te će $D W$ integralnu strukturu sačinjavati svi oni $D M$ ovi koje smo specificirali u paragrafu o delokrugu sistema poslovne inteligencije Fonda.

Višedimenzionalnost je najkarakterističnija osobina podataka za podršku odlučivanju. Posledica su činjenice da je, za donošenje poslovnih odluka, potrebno međusobno povezati i staviti u odnos, kako pojedinačne, tako i agregirane podatke o entitetima različitih klasa. Pri tome, podaci o pojedinačnim entitetima jedne klase predstavljaju jednu dimenziju, koja se povezuje sa nekim agregiranim podacima. Ti agregirani podaci opisuju ponašanje pojedinih entiteta posmatrane klase tokom određenog intervala vremena. Agregirani podaci se nazivaju činjenicama. Vreme predstavlja skoro obaveznu dimenziju podataka za podršku odlučivanju. Druge dimenzije su filijale, uplatioci doprinosa, teritorija, vrste osiguranja, rešenja, osiguranici, korisnici, referenti itd. Integralna $D W$ baza je baza od tridesetak tabela činjenica i oko 20 tabela dimenzija. Dakle, veoma kompleksan dimenzionalni model podataka. Ilustracije radi, prikazujemo samo jedan isečak tog logičkog dimenzionalnog modela, a koji se odnosi na DM_MAT-EVID-OSIG. (Sl. 2.)

Integralnim modelom $D W$ rukuje zaseban server $(D W$ Server), koji opslužuje rad sistema za upravljanje bazama podataka. Softver za upravljanje bazama podataka, na nivou fizičkog modela baze podataka, je IBM Informix Dynamic Server, na koji je implementiran $D W$ model. Ovakva analitička baza podataka je izvorište podataka za analitičke aplikacije pomoću kojih krajnji korisnici dolaze do izveštaja i analiziraju poslovanje organizacije.

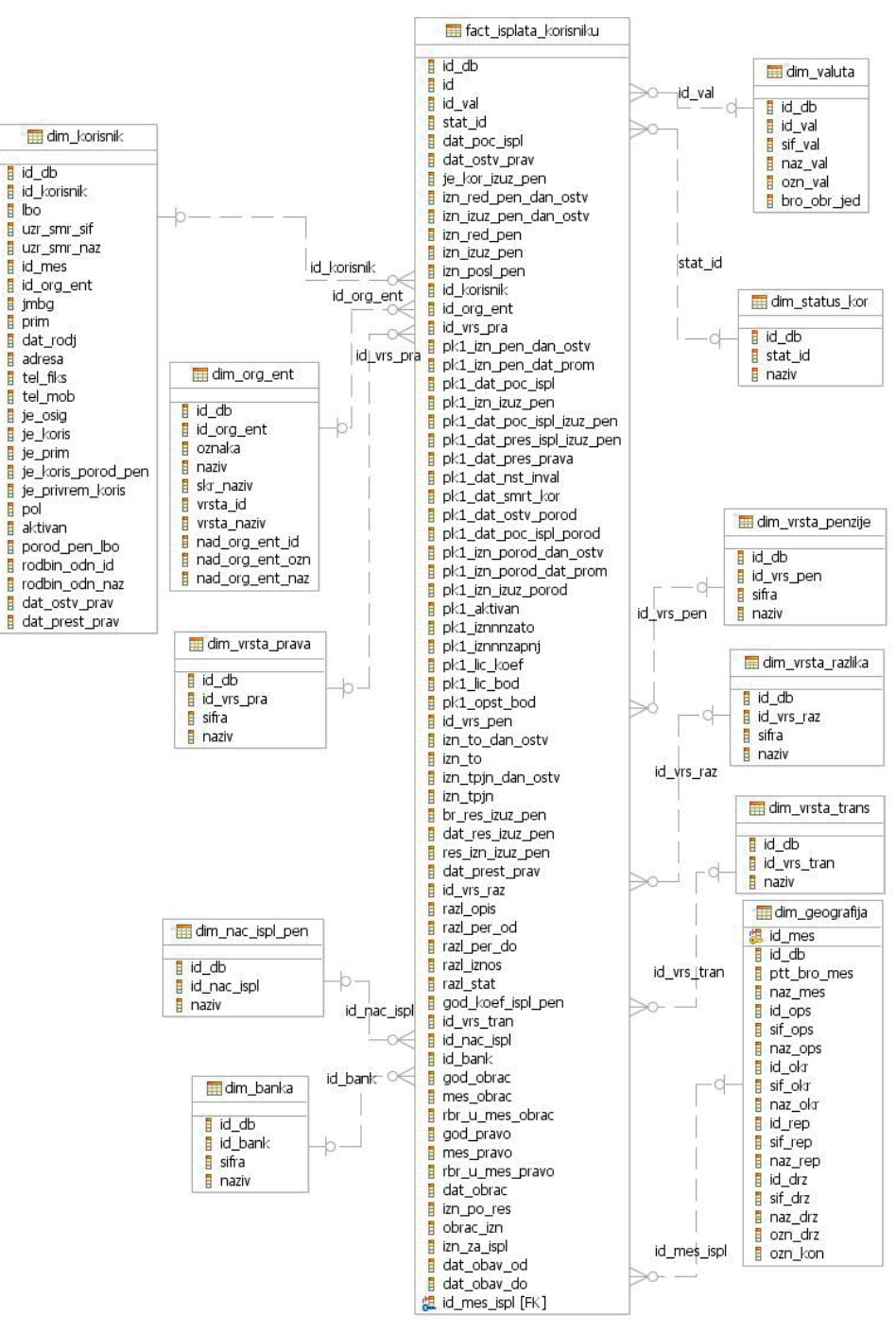

Sl. 2. Logički dimenzionalni model DM_MAT-EVID-OSIG

\section{OLAP SERVER}

OLAP Server se bavi analitičkom obradom podataka dobijenih iz $D W$-a. Nakon obrade podataka, rezultat se, prosleđuje WEB Serveru, a potom i krajnjem korisniku. Pored ovog procesa, OLAP Server vrši keširanje rezultata analiza, kao i njihovu auto-matsku distribuciju krajnjim korisnicima putem email-a, na štampač i/ili na File Server. Dakle, OLAP server rukuje sa funkcionalnostima i performansom OLAP alata, koji se koristiti kao front-end alat za analizu podataka i kreiranje mnogih izvještaja. Mnogo vrednih alata se danas nalazi na tržištu, kao što su IBM Cognos, Business Objects (SAP), Microstrategy Intelligence Server i mnogi drugi da bi podržali BI dashboard-e i druge tipove analitičkih aplikacija i izveštaja.

Softver koji je korišten u razvoju ovog proizvoda i koji se koristiti u implementaciji je Microstrategy Intelligence Server. Microstrategy Intelligence Server jedan je od najnaprednijih, skalabilan, siguran i robustan server poslovne inteligencije. On nudi osnovne analitičke obrade i upravljanje poslovima za sva izveštavanja, analize i praćenje primene. MicroStrategy Intelligence Server olakšava standardizaciju na jednoj, otvorenoj platformi za sve izveštaje i analize potreba u organizaciji kroz niz pristupa kanalima kao što su: Web pretraživači, Microsoft Office, desktop klijenata i e-pošte. 


\section{WEB SERVER}

Na WEB Serveru implementirane su sve sledeće analitičke aplikacije, na stotine predprogramiranih izveštaja i sa alatom koji omogućava ad hock izveštaje. WEB Server se brine o radu i sigurnosti svih navedenih aplikac ija.

\section{KRAJNJI KORISNICI I NJIHOVE APLIKACIJE}

Krajnji korisnici, iako geografski rasprostranjeni po celoj Republici Srpskoj imaju mogućnost pristupa, putem Intraneta i/ili Interneta, WEB Serveru i analitičkim aplikacijama putem kojih se kreiraju, sačinjavaju izveštaji i analiziraju podaci. Pored analitičkih aplikacija, korisnicima je omogućen pristup informacijama kroz Microsoft Office paket, kao i automatski, putem email-a, preko File servera i štampača. Kao krajnji korisnici pojavljuju se upravnici poslovnica i svi zaposleni u poslovnicama, zatim zaposleni u filijalama u svim odelenjima koji imaju odobren pristup i korisničku šifru pojedinim aplikacijama koje su im neophodne u svakodnevnom procesu rada.

\section{ZAKLJUČAK}

Rad u IIS-u ovakve kompozitne tehničke infrastrukture omogućava menadžmentu Fonda stavljanje pod potpunu kontrolu poslovnih tokova, pravovremeno i tačno dobijanje informacija na osnovu podataka iz vlastitih baza koji se dobijaju iz mnoštva generisanih i automatizovanih izveštaja.
Ovakva kontrola i raspolaganje potrebnim informacijama, menadžmentu Fonda dala je mogućnost stručnih analiziranja i donošenje kvalitetnih i pravovremenih odluka, čija primena će obezbediti kvalitet, efikasnost i ekonomičnost u poslovanju ove veoma važne institucije za svaku državu, pa i Republiku Srpsku. Savremeno poslovanje postaje praktično nemoguće bez uvođenja modernih sistema u upravljanju organizacijom, koje će omogućiti njeno uspešno prilagođavanje kompleksnim uslovima poslovanja.

\section{LITERATURA}

[1] Suknović, M., Krulj, D., Čupić, M., Projektovanje i razvoj DW, FON, Beograd, 2005.

[2] Čupić,M., Suknović, M., Odlučivanje, FON, Beograd, 2008.

[3] Balaban N., Ristić Ž.,Poslovna inteligencija, Ekonomski fakultet Subotica, 2006.

[4] Balaban, N, Ristić, Ž. „Sistemi podrške odlučivanja“, Ekonomski fakultet, Subotica, 1998.

[5] Suknović, M., Delibašić, B., Poslovna inteligencija i sistemi za podršku odlučivanju, FON, Beograd, 2010

[6] Milić, M., „Unapređenje procesa odlučivanja uz primenu sistema poslovne inteligencije", doktorska disertacija, Univerzitet Singidunum Beograd, 2014.

\section{COMPOZITE ANALYSIS TEHNIKAL INFRASTRUCTURE MODEL SPI_PIO_RS}

\begin{abstract}
:
Integrated Information System (IIS) PIO forms the heart of this institution from whose base is the source of information is necessary for the exercise of rights, reporting, planning, analysis and decision making. The purpose of this analysis is to show the infrastructure model of business intelligence PIO. The analysis includes a database that is used for decision support, and update their structuretion. As sources of information in the Fund PIO were identified: a database of key business processes, ERP databases, historical data, external and other relevant information. The original data for Data Warehouse (DW) base form transactional processes that occur in the following business processes and activities: M1records of the insured, M2-records user rights, M4-Receivership pensions, M5-Monitoring contribution collection (recording and monitoring contributions, reports), M8-obligation of (insert data needed to calculate the liabilities). All data generated by these processes and records are swarming around the core information system (CIS). These data also represent the strongest source DW database. All of these processes are bound to each other in an integrated information system PIO, and implemented with the help of four servers as follows: ETL, DW, OLAP and WEB. End users, although geographically spread over the entire Serbian Republic have the ability to access, via the Intranet and/or Internet, the WEB server and analytic applications through which are created, consisting of reports and analyze data, which is converted to the information needed for decision making, solving business tasks and achieve business goals.
\end{abstract}

\section{Key words:}

data,

database,

server,

decision making, an integrated information system. 